\title{
Reprodução do bagre amarelo, Cathorops spixii (Agassiz) (Siluriformes, Ariidae), da Baía de Pinheiros, região estuarina do litoral do Paraná, Brasil
}

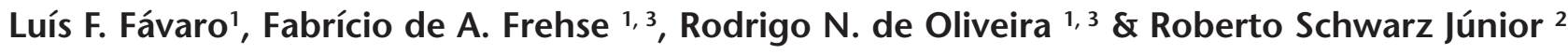 \\ 1 Departamento de Biologia Celular, Setor de Ciências Biológicas, Universidade Federal do Paraná. Caixa Postal 19031, \\ 81531-990 Curitiba, Paraná, Brasil. E-mail: lufavaro@ufpr.br \\ ${ }^{2}$ Centro de Estudos do Mar, Universidade Federal do Paraná. Avenida Beira Mar, 83255-000 Pontal do Paraná, Paraná, \\ Brasil. \\ ${ }^{3}$ Bolsista de Iniciação Científica (UFPR/TN).
}

\begin{abstract}
Reproduction of the Madamango sea catfish, Cathorops spixii (Agassiz) (Siluriformes, Ariidae), of the Pinheiros Bay, estuarine coastal area of Paraná, Brazil. The present study investigated the reproductive biology of Cathorops spixii (Agassiz, 1829) in Pinheiros Bay, littoral of Paraná State, Brazil. Fishes were captured monthly from June 2003 to May 2004 by using bottom trawls. For each individual, total body length, total weight, sex, and gonadal weight were recorded. The oogenesis (six ovarian follicle phases of development) and gonadal development stages (five stages) were also defined based on the histological examination of the ovaries. It was defined that the reproductive period of $C$. spixii extends from September to November, based on the analyses of individual gonadosomatic index (GSI) values distribution in relation to the sampling periods, on the monthly variation of the GSI mean values (Curve of Maturation), both for males and females, and on the monthly variation of the relative frequencies of the female maturation stages. The spawning period happened in the end of the spring and females with spawned ovaries were observed until middle autumn, among the months of November to April, being the spawning of the total type.
\end{abstract}

KEY WORDS. Oogenesis, histology, reproductive cycle.

RESUMO. O presente estudo investigou a biologia reprodutiva do bagre amarelo Cathorops spixii (Agassiz, 1829) na Baía de Pinheiros, litoral do Paraná, Brasil. Os peixes foram coletados mensalmente no período de junho de 2003 a maio de 2004 , com rede de arrasto de fundo. De cada exemplar foram tomados os dados de comprimento total, peso total, sexo e peso da gônada. As seis fases de desenvolvimento ovocitário (ovogênese) e os cinco estádios de desenvolvimento ovariano (escala de maturidade) foram determinadas por análises microscópicas dos ovários. Através dos valores individuais e media mensais do Índice gônado-somático (IGS) tratado para sexos separados, da freqüência relativa dos estádios de desenvolvimento ovariano e das análises histológicas durante o período de estudo foi possível determinar que o período reprodutivo de $C$. spixii dá-se entre os meses de setembro e novembro. Fêmeas apresentando ovários desovados ou em recuperação foram registradas nos meses de novembro a abril, com altos percentuais no período de dezembro a março. A desova foi caracterizada como sendo do tipo total.

PALAVRAS CHAVE. Ovogênese, histologia, ciclo reprodutivo.

A baía dos Pinheiros, área de estudo do presente trabalho, localiza-se na porção oriental do complexo estuarino de Paranaguá, Paraná, entre $25^{\circ} 27^{\prime} \mathrm{S}-25^{\circ} 14^{\prime} \mathrm{S}$ e $48^{\circ} 15^{\prime}-48^{\circ} 04^{\prime} \mathrm{W}$, tendo a ilha do Superagüí como limite a leste e a ilha das Peças como limite a oeste.

Os peixes denominados bagres marinhos pertencem à família Ariidae e são recursos pesqueiros abundantes em arrastos de fundo de zonas litorâneas tropicais, sendo considerados economicamente importantes na pesca artesanal na região Sul do Brasil (Reis 1986). Ocorrem em ambientes marinhos, estuarinos e de água doce, sendo freqüentes em águas costeiras pouco profundas e com fundos lodosos (ANDREATA et al. 1989, Azevedo et al. 1999).

O bagre amarelo, Cathorops spixii (Agassiz, 1829), objeto de estudo do presente trabalho, distribui-se de Belize (América Central) ao sul do Brasil, em profundidades de até $50 \mathrm{~m}$ (Figueiredo \& Menezes 1978), sendo este, o ariídeo mais freqüente e abundante na Baía dos Pinheiros e nos demais setores do 
Complexo Estuarino de Paranaguá. Esta espécie tem o ciclo de vida completo neste ambiente e é significativamente comercializada no mercado de peixes de Paranaguá, localizado na mesma região estuarina.

Dentre outras regiões, C. spixii foi considerado como importante recurso pesqueiro do complexo lagunar Mundaú/ Manguaba em Alagoas (Melo \& Teixeira 1992) e também no noroeste do caribe colombiano (Alvarez-Leon \& Rey-Carrasco 2003). No norte do Brasil, EspírITO SANTO \& IsAAC (1999) relataram a baixa importância de Cathorops spixii como recurso pesqueiro devido ao reduzido tamanho, embora esta espécie desempenhe um papel relevante no equilíbrio trófico dos ecossistemas nestes locais.

Cathorops spixii é muito citado em levantamentos ictiofaunísticos e em estudos de comunidades e pesca, realizados no litoral do Brasil e de outros países da América Central e do Sul, dentre estes estudos pode-se citar os de: Araújo et al. (1998a, b), Azevedo et al. (1998, 1999), CAstro (2001), Chaves et al. (2003) e SpACH et al. (2004). A abundância de C. spixii foi relatada, dentre outros, por IsAAC \& MOURA (1998), por BATISTA \& RÊGO (1996), por Araújo et al. (1998a) e por González Bencomo et al. (1997).

Estudos que relatam aspectos da reprodução de C. spixii foram realizados no estuário do Rio Caeté, no Pará (Espírito SANTO \& IsAaC 1999), no complexo Mundau/Manguaba em Alagoas (Melo \& Teixeira 1992), na Baía de Sepetiba, no Rio de Janeiro (Gomes et al. 1999) e na região estuarino-lagunar de Cananéia-Iguape, em São Paulo (Silva et al. 1998).

Na tentativa de entender o funcionamento do complexo estuarino de Paranaguá, no litoral do Paraná, faz-se necessário conhecer a biologia das espécies que nele habitam, bem como as suas relações com outras espécies e com os fatores abióticos. Algumas espécies estuarinas do referido local, tais como Sphoeroides greeleyi (Gilbert, 1900) (Schultz et al. 2002), Sphoeroides testudineus (Linnaeus, 1758) (Rосна et al. 2002) e Atherinella brasiliensis (Quoy \& Gaimard, 1825) (FÁvARo et al. 2003), já tiveram a sua reprodução analisada e assim, este trabalho fornece dados biológicos de mais uma espécie ecologicamente importante neste sistema.

O atual estudo visa conhecer aspectos do ciclo reprodutivo de Cathorops spixii, na baía de Pinheiros e suas relações com alguns fatores ambientais.

\section{MATERIAL E MÉTODOS}

Coletas mensais foram realizadas no período de junho de 2003 a maio de 2004 no canal principal da Baía de Pinheiros. Foi utilizada rede de arrasto de fundo de 9,3 m de comprimento, com malha de $1,3 \mathrm{~cm}$ no corpo e manga e $0,5 \mathrm{~cm}$ no ensacador. Foram capturados 629 exemplares da espécie Cathorops spixii, sendo 404 fêmeas e 225 machos.

Os exemplares tiveram os dados morfométricos tomados, comprimento total $(\mathrm{cm})$ e peso total $(\mathrm{g})$ e posteriormente, foram analisados macroscopicamente, quanto ao sexo e desenvolvimento gonadal. As gônadas foram retiradas, pesadas (g) e algumas fixadas em ALFAC por 18 horas, para a confecção de lâminas histológicas, processadas rotineiramente, incluídas em parafina e coradas com HE.

Os cortes histológicos foram analisados em microscópio de luz e permitiram a caracterização da ovogênese, a confecção de uma escala de maturidade para fêmeas e a correção da análise macroscópica, quando necessário.

O Índice Gônado-Somático (IGS), definido como a percentagem de participação do peso da gônada em relação ao peso total, foi estimado para cada indivíduo e analisado para sexos separados. Os valores médios mensais foram estimados e a partir da variação temporal, determinou-se a curva de maturação para machos e fêmeas. A determinação do tipo de desova foi baseada na distribuição de freqüência de ocorrência dos estádios de desenvolvimento ovariano e nas análises microscópicas dos ovários.

O ciclo reprodutivo da espécie foi relacionado com fatores físicos e químicos da água, tais como, temperatura, transparência, salinidade e $\mathrm{pH}$, os quais foram medidos mensalmente durante a coleta de material biológico.

A proporção sexual durante o ciclo reprodutivo foi testada pelo método do Qui-quadrado $\left(\chi^{2}\right)$, com grau de liberdade 1 e 0,05 de significância $\left(\chi^{2}<3,840\right)$, de acordo com VAzzolER (1996).

O tamanho de primeira maturação não foi estimado, visto que somente um indivíduo imaturo foi capturado.

\section{RESULTADOS E DISCUSSÃO}

\section{Ovogênese}

A diferenciação, o crescimento e o desenvolvimento das células germinativas femininas e das membranas envoltórias compreendem o processo de ovogênese. A partir da diferenciação das ovogônias em ovócitos, do surgimento de inclusões citoplasmáticas e de membranas foliculares, pode-se caracterizar as fases de desenvolvimento dos folículos ovarianos.

A dinâmica da ovogênese é que determinará a escala de maturidade das espécies e por sua vez, as táticas utilizadas pelas espécies para obterem sucesso reprodutivo no ambiente.

Para a espécie Cathorops spixii, a ovogênese foi descrita com seis fases de desenvolvimento dos folículos ovarianos (Tab. I e Figs 1-7).

Silva et al. (1998) relatam que em C. spixii, ainda na fase avitelogênica (correspondendo à fase II no presente trabalho), as células foliculares organizaram-se em duas camadas. No presente estudo foi verificada uma camada única de células foliculares, podendo o tecido conjuntivo adjacente organizarse com aspecto epitelioíde envolvendo os folículos, dando a impressão de uma outra camada de células foliculares.

\section{Escala de maturidade microscópica}

A utilização de análises histológicas na determinação dos estádios de desenvolvimento ovariano colabora para uma melhor compreensão do processo reprodutivo e diminui os erros contidos nas análises macroscópicas. 

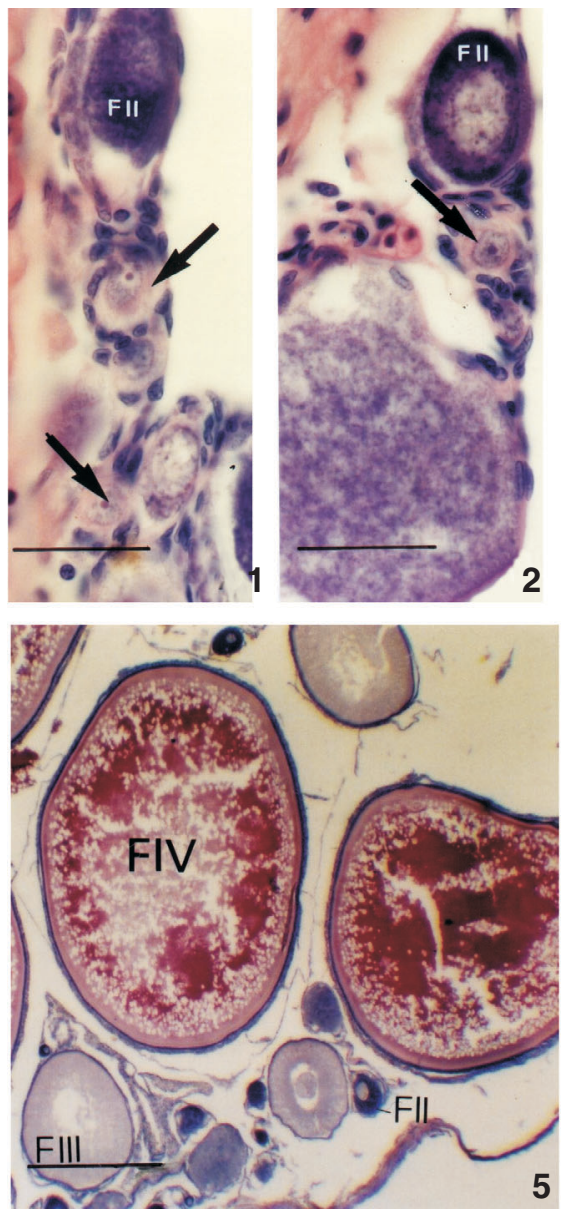
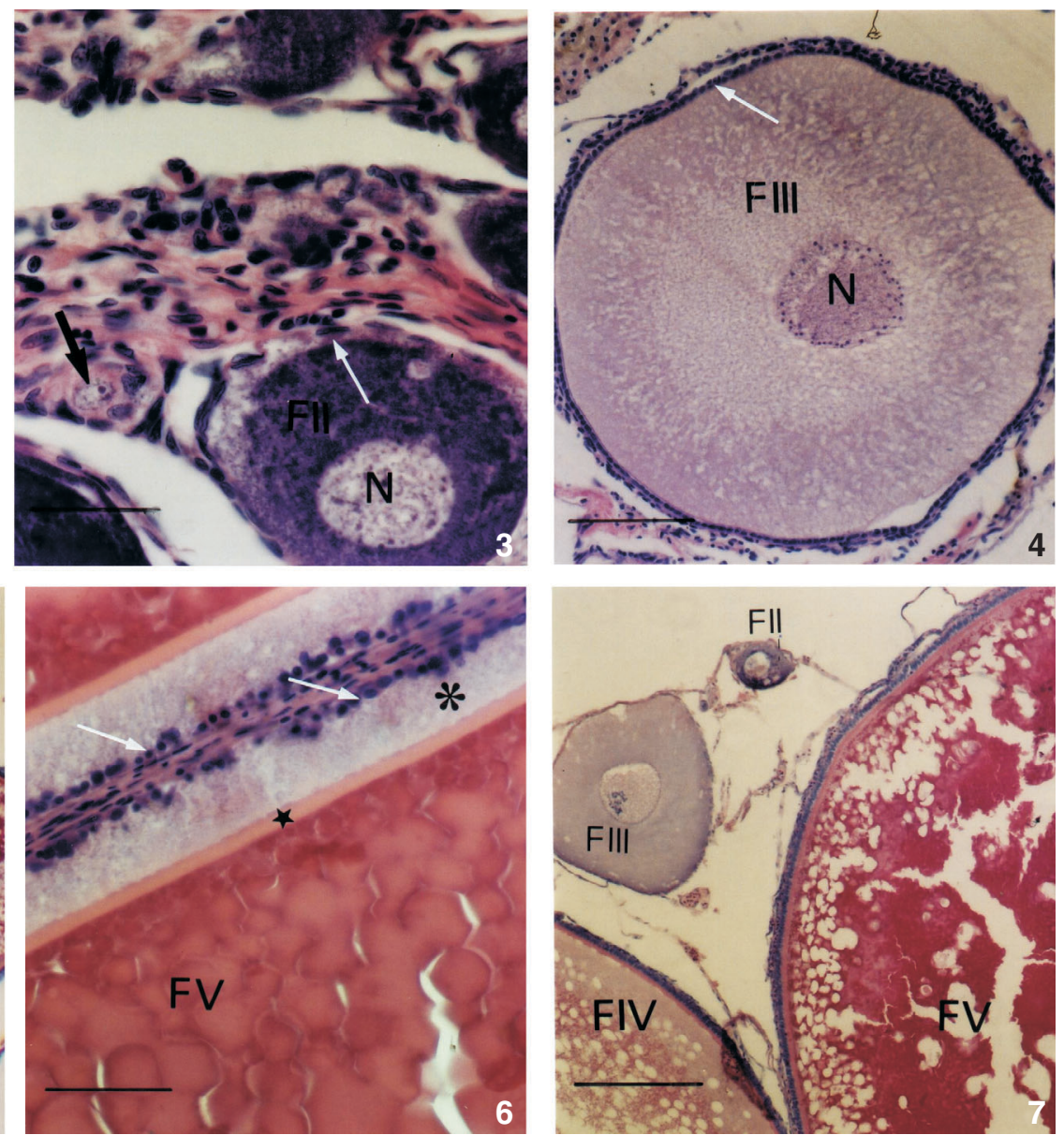

Figuras 1-7. Cortes histológicos de ovários de Cathorops spixii, corados com HE: (1-2) ovogônia (seta preta), folículo ovariano na fase II (F II), escala = $30 \mu \mathrm{m}$; (3) ovogônia (seta preta), folículo ovariano na fase II (F II), núcleo do ovócito (N), células foliculares na fase II (seta branca), escala = $30 \mu \mathrm{m}$; (4) folículo ovariano na fase III (F III), núcleo do ovócito (N), células foliculares (seta branca), escala = $90 \mu \mathrm{m}$; (5) folículos ovarianos nas fases II (F II), III (F III) e IV (F IV), escala = $450 \mu \mathrm{m}$; (6) folículo ovariano na fase V (F V), núcleos das células foliculares (setas brancas), citoplasma das células foliculares ( ${ }^{*}$ ), membrana vitelina (estrela), escala $45 \mu$ m; (7) folículos ovarianos nas fases II (F II), III (F III) e IV (F IV) e V (F V), escala $=180 \mu \mathrm{m}$.

Tabela I. Ovogênese de Cathorops spixii. Fases dos folículos ovarianos e suas respectivas características.

\begin{tabular}{llll}
\hline FASE I (ovogônias) & \multicolumn{2}{l}{ Células pequenas, núcleo grande e central com nucléolo único e basófilo, citoplasma escasso (Figs 1, 2 e 3) } \\
& Ovócito (citoplasma) & Células foliculares & Membrana vitelina \\
\hline FASE II (Figs 1, 2 e 3) & Basófilo (sem inclusões) & Pavimentosa & Ausente \\
FASE III (Figs 4, 5 e 7) & Vesículas citoplasmáticas & Pavimentosa/cúbica & Delgada \\
FASE IV (Figs 5 e 7) & Vesículas e grânulos & Cúbica & Espessa \\
FASE V (Figs 6 e 7) & Grânulos de vitelo & Cúbica/cilíndrica & Espessa \\
FASE VI & Hialinizado & Cilíndrica & Espessa \\
\hline
\end{tabular}

Folículos atrésicos, vazios e corpos residuais* não foram considerados como fases do processo de ovogênese e sim como estruturas derivadas de tal processo.

* Os corpos residuais são estruturas que podem ser originadas a partir dos folículos vazios, organizando-se em uma massa celular, a qual muitas vezes não tem afinidade pelos corantes utilizados (HE), adquirindo coloração em tom castanho.

Revista Brasileira de Zoologia 22 (4): 1022-1029, dezembro 2005 
O fato de se investir na microscopia de ovários ocorre por ser a ovogênese mais complexa que a espermatogênese, pois a fêmea além de produzir o gameta feminino é ainda responsável pela incorporação de nutrientes nos ovócitos, para serem utilizados nas primeiras fases de vida dos alevinos (FÁvaro et al. 2003). Outro aspecto relevante é que as células da linhagem gamética feminina são maiores que as células da linhagem espermática, fator facilitador nas análises microscópicas.

A escala de maturidade microscópica (Tab II), confeccionada para fêmeas de C. spixii, está composta por cinco estádios de desenvolvimento ovariano e foi baseada na ocorrência e na quantidade das fases de desenvolvimento do folículo ovariano e nas estruturas derivadas do processo de ovogênese.

O ovário em maturação, estádio B (Fig. 8), apresenta-se diferente do encontrado em outras espécies, sendo comum observar corpos residuais e algumas poucas vezes, folículos vazios juntamente com folículos ovarianos em fase de desenvolvimento avançado (Fases III e IV). Estas análises indicam que a reabsorção dos folículos vazios ocorre de forma lenta e que este estádio pode ser confundido com um estádio parcialmente desovado.

Os ovários maduros (Fig. 9) apresentam-se, inicialmente, com grande quantidade de folículos ovarianos na fase $\mathrm{V}$ e menores quantidades de folículos ovarianos nas fases II, III e IV. Posteriormente, estes ovários com o mesmo conteúdo de folículos ovarianos, mostram-se maiores e mais pesados, refletindo em um maior valor da relação gônado-somática. As análises histológicas permitiram evidenciar que a única modificação ocorrida foi em relação ao volume da gônada e não na ocorrência e abundância das diferentes fases dos folículos ovarianos.

Em geral, as espécies ícticas após a desova apresentam o ovário com as lamelas ovulígeras muito desorganizadas e com muito tecido conjuntivo. Folículos vazios, ovogônias e folículos ovarianos na fase II são comumente encontrados. No estádio D ou desovado de C. spixii, o ovário apresenta muitos folículos vazios juntamente com ovogônias e folículos ovarianos nas fases
II e III, o que não é comum para a maioria dos teleósteos.

Os ovários desovados (estádio D) (Fig. 10) caracterizamse por apresentar muitos folículos vazios e folículos em vitelogênese avançada em menor quantidade. Neste estádio, alguns folículos ovarianos que alcançaram a fase $\mathrm{V}$ e não foram eliminados (desovados), entram no processo de atresia, sendo reabsorvidos (Fig. 11).

O estádio E ou recuperação foi caracterizado pela presença de folículos ovarianos nas fases II e III e ainda por grande quantidade de corpos residuais e alguns folículos vazios.

Os folículos atrésicos, vazios e corpos residuais, os quais não foram considerados como fases no processo de desenvolvimento dos folículos ovarianos (ovogênese), são importantes na dinâmica do processo reprodutivo e desempenharam papel importante na confecção da escala de maturidade. A presença e a quantidade destas estruturas foram utilizadas para caracterizar os estádios de desenvolvimento do ovário, principalmente os estádios desovado e recuperação (pós-desova).

SiLva et al. (1998) descreveram uma escala de maturidade microscópica para a espécie em questão, incluindo o estádio de recuperação. Os autores supracitados relataram a presença de corpos residuais, como os mencionados no presente estudo. Gomes et al. (1999) não trabalharam com análises histológicas, sendo sua escala de maturidade baseada em macroscopia, contendo cinco estádios e não havendo o estádio em recuperação.

\section{Ciclo reprodutivo}

Considerando-se que os valores de IGS médio, utilizados na confecção da curva de maturação, poderiam mascarar a média mensal do IGS individual dos indivíduos de cada sexo, a análise da distribuição dos valores individuais do IGS para os diferentes sexos, foi utilizada no presente estudo com o objetivo de verificar o desenvolvimento das gônadas dos indivíduos de uma população, permitindo uma análise mais real e precisa.

Foi possível evidenciar, a partir da análise gráfica da distribuição dos valores individuais do IGS de fêmeas e machos

Tabela II. Escala de maturidade para fêmeas de Cathorops spixii, baseada nas características microscópicas dos ovário.

\begin{tabular}{|c|c|c|}
\hline Estádios & Características microscópicas & IGS Médio \\
\hline (A) Imaturo & Presença de ovogônias (fase I) e folículos ovarianos na fase II. & 0,2765 \\
\hline (B) Maturação & $\begin{array}{l}\text { Observa-se inicialmente, a presença abundante de folículos ovarianos nas fases II e III. Com o avanço } \\
\text { no desenvolvimento deste estádio, os folículos ovarianos na fase IV aumentam em número e alguns na } \\
\text { fase } V \text { podem ser observados. Pode ocorrer neste estádio a presença de corpos residuais e ainda poucos } \\
\text { folículos vazios. }\end{array}$ & 0,5248 \\
\hline (C) Maduro & $\begin{array}{l}\text { Neste estádio poucos folículos ovarianos nas fases II e III são observados. Folículos ovarianos na fase IV } \\
\text { são observados, mas o predomínio é de folículos na fase V e VI (em início de hialinização). Indivíduos } \\
\text { "desovando" foram classificados como maduros, portanto, algumas gônadas maduras podem conter } \\
\text { além de muitos folículos ovarianos nas fases V e VI, poucos folículos vazios. }\end{array}$ & 5,0068 \\
\hline (D) Desovado & $\begin{array}{l}\text { Observa-se folículos ovarianos nas fases II e III juntamente com grande quantidade de folículos vazios. } \\
\text { Poucos folículos ovarianos nas fases IV, V e VI são evidenciados. Pode ocorrer folículos atrésicos. }\end{array}$ & \\
\hline (E) Recuperação & $\begin{array}{l}\text { Neste estádio verifica-se a presença de folículos ovarianos nas fases II e III juntamente com quantidade } \\
\text { significativa de corpos residuais. Folículos vazios ainda podem ser visualizados, mas agora em } \\
\text { quantidade menor se comparado ao estádio anterior. }\end{array}$ & 0,460 \\
\hline
\end{tabular}



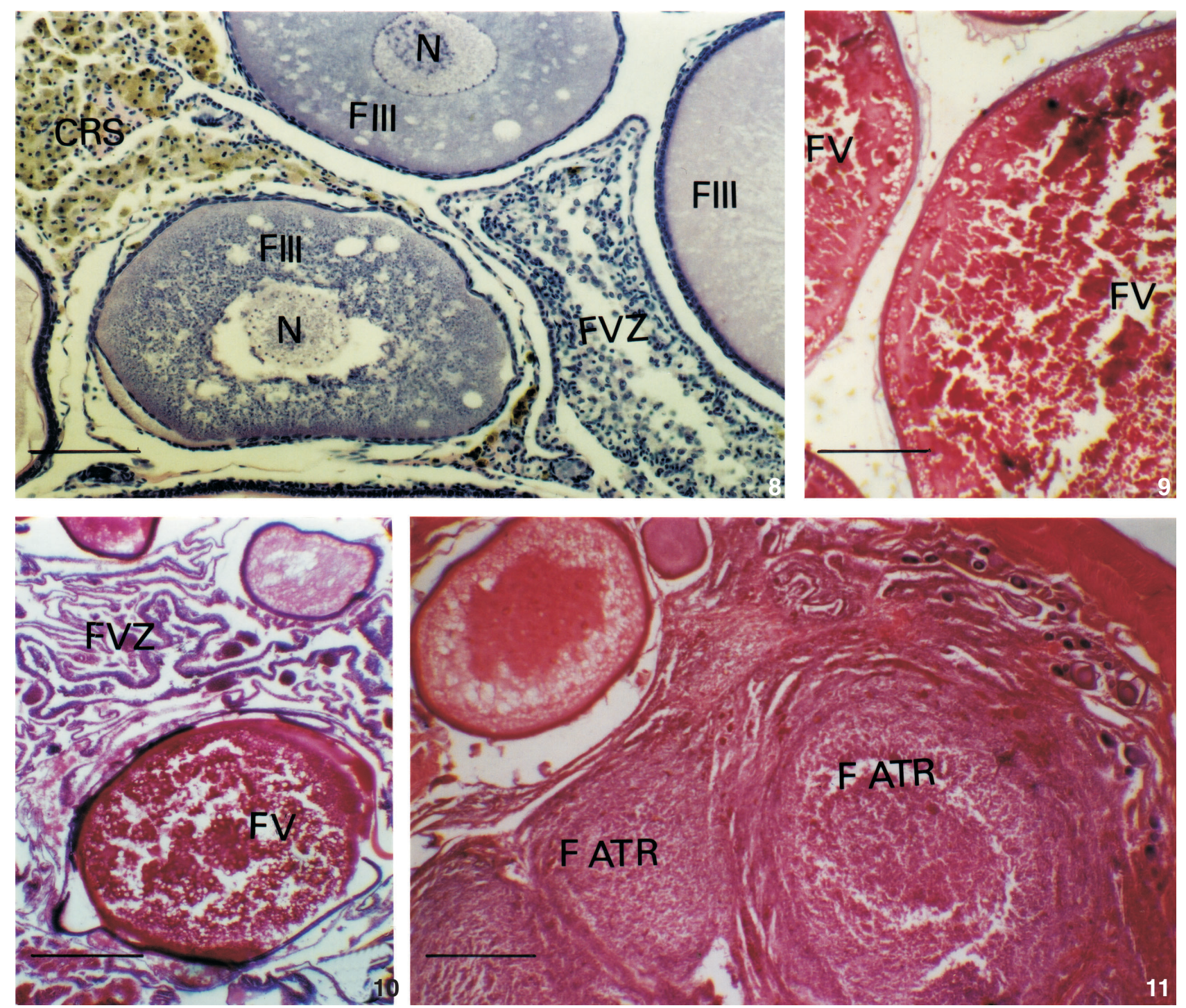

Figuras 8-11. Cortes histológicos de ovários de Cathorops spixii, corados com HE: (8) ovário em maturação: folículos ovarianos na fase III (F III), núcleo do ovócito (N), corpo residual (CRS) e folículo vazio (FVZ), escala = $90 \mu \mathrm{m}$; (9) ovário maduro contendo folículos ovarianos na fase V (F V), escala = $450 \mu \mathrm{m}$; (10) ovário desovado: muitos folículos vazios (FVZ) e folículo ovariano na fase V (F V), escala = $450 \mu \mathrm{m}$; (11) ovário desovado: folículos ovarianos em atresia (F ATR), escala $=450 \mu \mathrm{m}$.

de C. spixii (Fig. 12), que o desenvolvimento gonadal ocorre de forma rápida, sendo bastante expressivo no período de setembro a outubro para ambos os sexos. O mesmo resultado foi constatado também na curva de maturação de fêmeas e machos da referida espécie (Fig. 13), a qual utiliza a média mensal do IGS para sexos separados.

No mês de outubro os indivíduos atingiram os maiores valores de IGS individuais.

Indivíduos machos apresentaram uma queda drástica nos valores do IGS no mês de novembro, entendendo-se que neste período ocorreu o esvaziamento dos testículos de forma mais eficaz. Para as fêmeas, a queda nos valores do IGS deu-se de novembro a janeiro, correspondendo ao período de desova (Figs 12 e 13).

A curva de maturação elaborada para a espécie, demonstrou que o desenvolvimento das gônadas masculinas e femininas, atingindo altos valores de IGS médio, ocorreu no mesmo período, bem como a queda dos referidos valores, caracterizando o período de eliminação de gametas da espécie (Fig. 13).

Na Baía de Sepetiba, Gomes et al. (1999) encontraram pi-

Revista Brasileira de Zoologia 22 (4): 1022-1029, dezembro 2005 

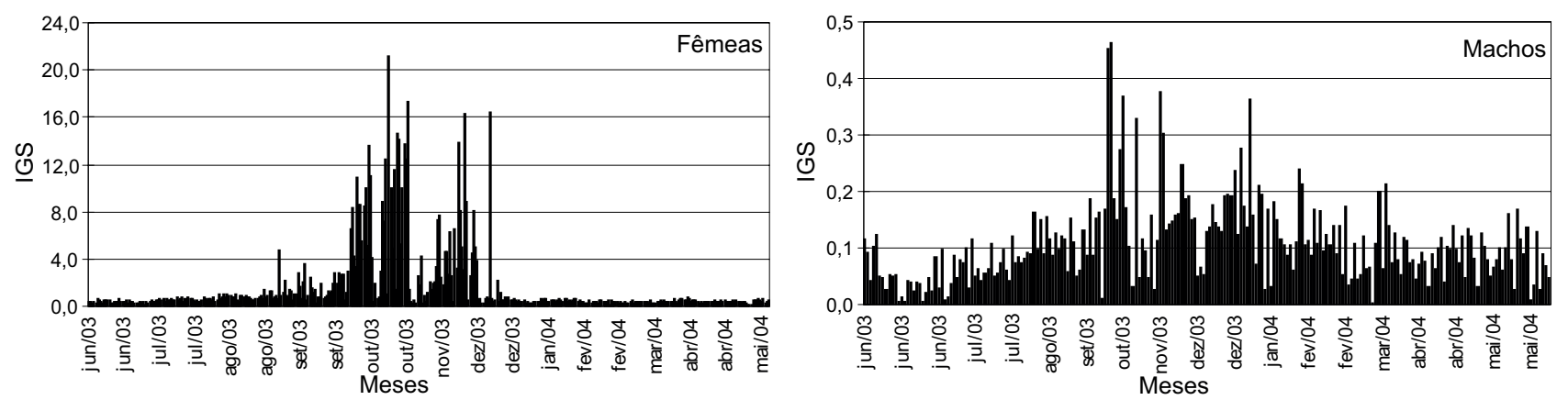

Figura 12. Distribuição mensal dos valores individuais do IGS de fêmeas e machos no período estudado.

cos de IGS em épocas distintas para machos e fêmeas, para a mesma espécie analisada neste estudo. Possivelmente esta diferença deu-se em decorrência da metodologia utilizada, onde as coletas ocorreram bimestralmente.

A análise da distribuição mensal de freqüência de ocorrência dos estádios de desenvolvimento ovariano (Fig. 14) constatou que fêmeas maduras foram observadas significativamente, nos meses de setembro, outubro e novembro e quantidade pouco expressiva no mês de dezembro. Fêmeas apresentando ovários desovados ou em recuperação foram registradas nos meses de novembro a abril, com altos percentuais no período de dezembro a março. Os resultados obtidos pela análise da distribuição mensal de freqüência de ocorrência dos estádios de maturação ovariana, corroboram com a curva de maturação da espécie.

Muitos exemplares machos capturados nos meses de novembro, dezembro e janeiro, apresentaram-se incubando ovos já fertilizados e em diferentes estágios de desenvolvimento embrionário, fato este que reafirma a desova neste período.

EsPírito SANTO \& IsAAC (1999) relataram a ocorrência de machos e fêmeas de C. spixii incubando ovos no estuário do Rio Caeté, no Pará, diferentemente do observado na Baía de Pinheiros, onde somente os machos foram observados desempenhando esta função.

A associação das análises de distribuição dos valores individuais do IGS, curva de maturação, freqüência relativa dos estádios de maturação dos ovários, juntamente com a análise histológica, permitiu determinar a ocorrência do período reprodutivo na primavera, entre os meses de setembro a novembro, corroborado pela alta freqüência de ocorrência de fêmeas com ovários maduros. O período de desova ocorreu no final da primavera e fêmeas com ovários desovados foram observadas até meados do outono, entre os meses de novembro a abril, sendo a desova do tipo total.

Na Baía de Pinheiros, o período reprodutivo e de esvaziamento das gônadas para os machos deve ser o mesmo determinado para as fêmeas, visto que a curva de maturação mostrou um desenvolvimento gonadal sincronizado entre fêmeas e machos de C. spixii.

Gomes et al. (1999) a partir do estudo realizado na Baía de
Sepetiba, no Rio de Janeiro, sugeriram o período entre a primavera e o início do verão para a reprodução de C. spixii, coincidindo com os resultados do presente trabalho. A desova total também foi verificada por Gomes et al. (1999).

No complexo lagunar Mundaú/Manguaba, Melo \& Teixeira (1992) relataram que o amplo período reprodutivo de C. spixii estendeu-se da primavera ao outono, sendo que fêmeas maduras foram observadas de outubro a maio e o maior valor de IGS deu-se no mês de dezembro.

Durante o período de coletas, os parâmetros físicos e químicos da água pouco se alteraram (Fig. 15). As amplitudes de variação foram de $6,4^{\circ} \mathrm{C}$ para a temperatura, $1,4 \mathrm{~m}$ para a transparência da água, 3,6\%o para a salinidade e de 0,7 para o $\mathrm{pH}$.

A época da desova coincidiu com o período de temperaturas mais altas, o que nos permite inferir que a elevação da temperatura seja importante no desenvolvimento embrionário.

Gomes et al. (1999) relataram que no período reprodutivo de C. spixii na Baía de Sepetiba, os valores de temperatura e transparência da água estavam em elevação, enquanto a salinidade diminuía.

No complexo lagunar Mundaú/Manguaba, a salinidade atingiu no máximo $16,8 \%$ e mais de $90 \%$ dos espécimes foram capturados em áreas com salinidade menor que 7\%o (Melo \& TeIXEIRA 1992). Resultados diferentes foram revelados na Baía de Pinheiros, onde os valores de salinidade variaram de $27,5 \%$ a $31,2 \%$.

As diferenças ou as semelhanças nos períodos reprodutivos de C. spixii que foram observadas em distintos locais, provavelmente devem-se a estrutura das comunidades que habitam as diferentes áreas, bem como a variação dos parâmetros ambientais, as quais exercem de forma conjunta pressões diferentes para cada área analisada. Por isso a necessidade de se conhecer a biologia das espécies, e também os locais onde as mesmas se encontram.

O predomínio de fêmeas sobre machos foi evidenciado praticamente durante todo o período de estudo. A proporção sexual durante o período reprodutivo (Tab. III), apresentou valores significativos $\left(\chi^{2}>3,840\right)$ mostrando uma relação aproximada de quatro fêmeas para cada macho (4:1).

No presente trabalho, o maior e o menor comprimento

Revista Brasileira de Zoologia 22 (4): 1022-1029, dezembro 2005 

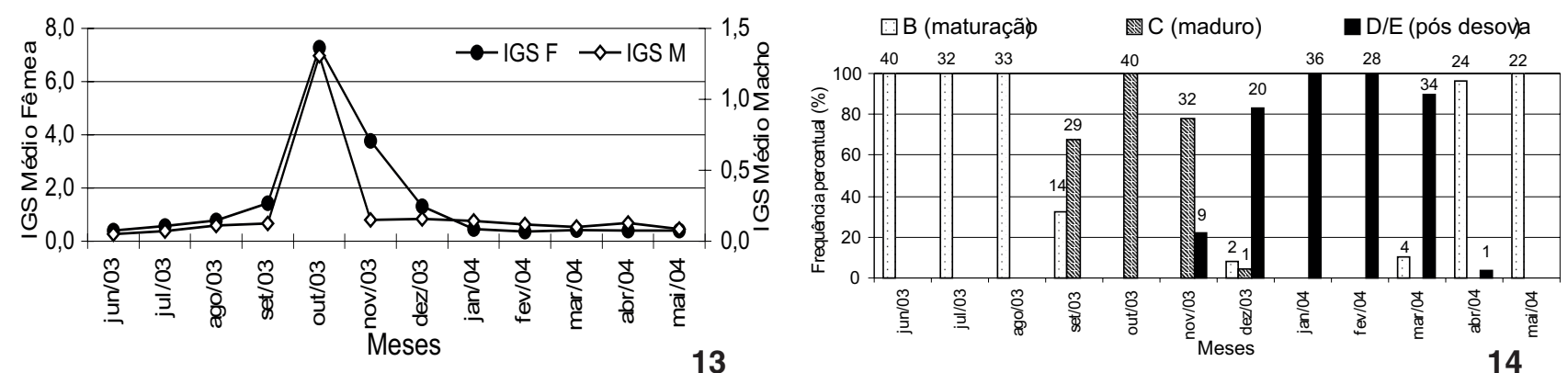

Figuras 13-14. Cathorops spixii. (13) Curva de maturação para fêmeas e machos de: (IGS F) IGS médio mensal de fêmeas e (IGS M) IGS médio mensal de machos; (14) freqüência percentual (\%) mensal dos estádios de desenvolvimento ovariano: (B) maturação, (C) maduro, (D/E) desovado/recuperação. Números sobre as barras denotam a freqüência absoluta.



Figura 15. Variação mensal dos parâmetros físicos e químicos dá água: temperatura, transparência, salinidade e $\mathrm{pH}$, na Baía de Pinheiros, litoral do Paraná.

Tabela III. Cathorops spixii. Freqüência absoluta de fêmeas (n F) e machos $(\mathrm{n} \mathrm{M})$ e $\chi^{2}(\mathrm{gl}=1)$. (*) Significativo ao nível de $5 \%$.

\begin{tabular}{lcccc}
\hline \multicolumn{1}{c}{ Meses } & N F & n M & Total & \multicolumn{1}{c}{$\chi^{2}$} \\
\hline Jun/2003 & 42 & 35 & 77 & 0,64 \\
Jul/2003 & 32 & 18 & 50 & $3,92^{*}$ \\
Ago/2003 & 33 & 17 & 50 & $5,12^{*}$ \\
Set/2003 & 43 & 7 & 50 & $25,92^{*}$ \\
Out/2003 & 40 & 11 & 51 & $16,49^{*}$ \\
Nov/2003 & 41 & 11 & 52 & $17,31^{*}$ \\
Dez/2003 & 23 & 27 & 50 & 0,32 \\
Jan/2004 & 37 & 13 & 50 & $11,52 *$ \\
Fev/2004 & 28 & 21 & 49 & 1,00 \\
Mar/2004 & 38 & 12 & 50 & $13,52 *$ \\
Abr/2004 & 25 & 25 & 50 & 0,00 \\
Mai/2004 & 22 & 28 & 50 & 0,72 \\
\hline Total & 404 & 225 & 629 & $50,94 *$ \\
\hline
\end{tabular}

total para fêmea foi respectivamente, 22,4 e $10,4 \mathrm{~cm}$. O maior e o menor macho apresentaram os comprimentos totais de 22,9 e $10,6 \mathrm{~cm}$, respectivamente. A fêmea com o menor tamanho foi o único exemplar no estádio imaturo. Este resultado mostra-se pertinente com o estudo realizado por EspíRITO SANTO \& IsAAC (1999) em estuário no estado do Pará, onde somente indivíduos com mais de $10 \mathrm{~cm}$ participaram das atividades reprodutivas. Melo \& Teixeira (1992) observaram espécimes de C. spixii com o comprimento total variando entre 3,3 e $25 \mathrm{~cm}$ e estabeleceram o comprimento de maturação para fêmeas e machos de C. spixii em torno de $12 \mathrm{~cm}$. A população de bagres da mesma espécie, na Baía de Sepetiba, apresentou os comprimentos totais variando de 9,1 a 32,5 cm (Gomes et al. 1999).

A utilização da histologia como ferramenta de trabalho permite relacionar características microscópicas da ovogênese com a ecologia reprodutiva de Cathorops spixii.

Os ovócitos nas fases V e VI são muito volumosos e em contra partida, as fêmeas produzem-nos em números reduzidos. As células foliculares sofrem modificações no decorrer da ovogênese, iniciando o processo com forma pavimentosa, passando a cúbica e terminando como cilíndricas nas fases mais desenvolvidas. Possivelmente as células foliculares cilíndricas adquirem maquinaria necessária à síntese de material aderente, utilizado na adesão dos ovos após sua liberação no meio externo. A adesão dos ovos age como um facilitador para as espécies que nidificam ou cuidam da prole.

Através das análises histológicas foi possível verificar que as fêmeas da espécie Cathorops spixii produzem um número pequeno de ovócitos, os quais apresentam grande volume quando desenvolvidos. Os ovos são adesivos, a desova é total e a espécie exibe cuidado parental. As táticas utilizadas visam alcançar sucesso reprodutivo para a espécie conferindo uma tendência Kestrategista.

\section{REFERÊNCIAS BIBLIOGRÁFICAS}

Alvarez-Leon, R. \& I. Rey-Carrasco. 2003. Fauna extraida en la exploración del barco M/N "Vikheim" al noroeste del Caribe colombiano. Revista de Biologia Tropical, San José, 51 (2):

Revista Brasileira de Zoologia 22 (4): 1022-1029, dezembro 2005 
551-554.

Andreata, J.V.; L.R.R. Barbieri; A.S.B.Sebilia; M.H.C. Silva \& R.P. SANTOS. 1989. A list of Marapendi Lagoon fishes, Rio de janeiro, Brazil. Atlântica, Rio Grande, 11: 5-17.

Araújo, F.G.; A.G. Cruz-Filho; M.C.C. Azevêdo \& A.C.A. Santos. 1998a. Estrutura da comunidade de peixes demersais da baía de Sepetiba, RJ. Revista Brasileira de Biologia, São Carlos, 58 (3): 417-430.

Araújo, F.G.; A.L.M. Pessanha; M.C.C. Azevedo \& I.D. Gomes. 1998b. Relação peso-comprimento de bagres marinhos (Siluriformes, Ariidae) na Baía de Sepetiba, RJ. Acta Biológica Leopoldensia, São Leopoldo, 20: 289-298.

Azevedo, M.C.C.; F.G. Araujo; A.G. Cruz-Filho \& A.C.A. Santos. 1998. Distribuição e abundância relativa de bagres marinhos (Siluriformes, Ariidae) na Baia de Sepetiba, Rio de Janeiro. Revista Brasileira de Zoologia, Curitiba, 15 (3): 853-865.

Azevedo, M.C.C.; F.G. Araujo; A.G. Cruz-Filho; I.D. Gomes \& A.L.M. Pessanha. 1999. Variação espacial e temporal de bagres marinhos (Siluriformes, Ariidae) na baía de Sepetiba, Rio de Janeiro. Revista Brasileira de Biologia, São Carlos, 59 (3): 443-454.

BAtista, V.S. \& F.N. RÊGo. 1996. Análise da associação de peixes, em igarapés do estuário do Rio Tibiri, Maranhão. Revista Brasileira de Biologia, Rio de Janeiro, 56 (1): 163-176.

CAstro, A.C.L. 2001. Diversidade da assembléia de peixes em igarapés do estuário do rio Paciência (MA - Brasil). Atlântica, Rio Grande, 23: 39-46.

Chaves, P.T.; G. Cova-Grando \& C. Calluf. 2003. Demersal ichthyofauna in a continental shelf region on the south coast of Brazil exposed to shrimp trawl fisheries. Acta Biológica Paranaense, Curitiba, 32 (1, 2, 3, 4): 69-82.

Espírito SANTO, R.V. \& V.J. IsaAc. 1999. Alimentação e aspectos da reprodução da Uricica, Cathorops spixii (Agassiz, 1829) (Osteychthyes, Siluriformes, Ariidade), no estuário do Rio Caeté (Município de Bragança-PA). Boletim do Museu paraense Emílio Goeldi, Série Zoologia, Belém, 15 (1): 95 111.

FÁVARO, L.F.; S.C.G. LoPES \& H.L. SPACH. 2003. Reprodução do peixe-rei, Atherinella brasiliensis (Quoy \& Gaimard) (Atheriniformes, Atherinidae), em uma planície de maré adjacente à gamboa do Baguaçu, Baía de Paranaguá, Paraná, Brasil. Revista Brasileira de Zoologia, Curitiba, 20 (3): 501-506.

Figueiredo, J.L. \& N.A. Menezes. 1978. Manual de Peixes Marinhos do Sudeste do Brasil. II. Teleósteos (1). São Paulo,
Museu de Zoologia, Universidade de São Paulo, 116p.

Gomes, I.D.; F.G. Araújo; M.C.C. Azevedo \& A.L.M. Pessanha. 1999. Biologia reprodutiva dos bagres marinhos Genidens genidens (Valencianes) e Cathorops spixii (Agassiz) (Siluriformes, Ariidae) na Baía de Sepetiba, Rio de Janeiro, Brasil. Revista Brasileira de Zoologia, Curitiba, 16 (2): 171-180.

Gonzalez Bencomo, E.J.; J.A. Borjas \& E.C. Castillo. 1997. Ictiofauna del sector San Carlos del Lago de Maracaibo. Venezuela. Boletín del Centro de Investigaciones Biológicas, Maracaibo, 31 (2): 151-179.

IsAaC, V.J. \& U.S. Moura. 1998. Taxa de consumo alimentar de três populações de peixes do estuário do Rio Caeté, BragançaPA, no litoral do norte do Brasil. Boletim do Museu paraense Emílio Goeldi, Série Zoologia, Belém, 14 (1): 57 75.

Melo, S.C. \& R.L. TeixeIra. 1992. Distribuição, reprodução e alimentação de Cathorops spixii e Arius rugispinis (Pisces, Ariidae) do complexo Mundaú/Manguaba, Maceió-AL. Revista Brasileira de Biologia, Rio de Janeiro, 52 (1): 169-180.

ReIs, E.G. 1986. A pesca artesanal de bagres marinhos (Siluriformes, Ariidae) no estuário da Lagoa dos Patos (RS). Rio Grande, Fundação Universidade do Rio Grande, Documentos Técnicos, vol. 5, 21p.

Rocha, C.; L.F. Fávaro \& H.L. Spach. 2002. Biologia Reprodutiva de Sphoeroides testudineus (Linnaeus), Pisces, Osteichthyes, Tetraodontidae, da Gamboa do Baguaçu, Baía de Paranaguá, Paraná, Brasil. Revista Brasileira de Zoologia. Curitiba, 19 (1): 57-63.

Schultz, Y.D.; L.F. Fávaro \& H.L. Spach. 2002. Aspectos Reprodutivos de Sphoeroides greeleyi (Gilbert), Pisces, Osteichthyes, Tetraodontidae, da Gamboa do Baguaçu, Baia de Paranaguá, Paraná, Brasil. Revista Brasileira de Zoologia. Curitiba, 19 (1): 65-76.

Silva, J.P.; A.M. PaIva Filho \& N.S. ReIs. 1998. Caracterização macro e microscópica dos ovários do bagre amarelo, Cathorops spixii (Agassiz, 1829), durante o ciclo reprodutivo. Revista Brasileira de Ocenografia, São Paulo, 46 (2): 171-185.

Spach, H.L.; R.S. Godefroid; C. SANTos; R. Schwarz JR. \& G.M.L. DE Queiroz. 2004. Temporal variation in fish assemblage composition on a tidal flat. Brazilian Journal of Oceanography, São Paulo, 52 (1): 47-58.

VAZzolER, A.E. DE M. 1996. Biologia da reprodução de peixes teleósteos: teoria e prática. Maringá, Editora Universidade Estadual de Maringá, 169p.

Recebido em 07.IV.2005; aceito em 06.XI.2005. 